\title{
The relationship between energy consumption, economic growth and carbon dioxide emissions in Pakistan
}

\author{
Muhammad Kamran Khan ${ }^{*}$ (D, Muhammad Imran Khan and Muhammad Rehan
}

\author{
* Correspondence: \\ kamrankhanaup@gmail.com \\ School of Economics, Northeast \\ Normal University, Changchun, Jilin, \\ China
}

\begin{abstract}
Developing countries are facing the problem of environmental degradation. Environmental degradation is caused by the use of non-renewable energy consumptions for economic growth but the consequences of environmental degradation cannot be ignored. This primary purpose of this study is to investigate the nexus between energy consumption, economic growth and $\mathrm{CO}_{2}$ emission in Pakistan by using annual time series data from 1965 to 2015. The estimated results of ARDL indicate that energy consumption and economic growth increase the $\mathrm{CO} 2$ emissions in Pakistan both in short run and long run. Based on the estimated results it is recommended that policy maker in Pakistan should adopt and promote such renewable energy sources that will help to meet the increased demand for energy by replacing old traditional energy sources such as coal, gas, and oil. Renewable energy sources are reusable that can reduce the $\mathrm{CO} 2$ emissions and also ensure sustainable economic development of Pakistan.

Keywords: Energy consumption, Economic growth, CO2 emissions, ARDL
\end{abstract}

\section{Introduction}

Pakistan is a developing country in South Asian countries, economy of Pakistan is growing rapidly and it is expected that the economic growth of Pakistan will continue with same trend in the future. Pakistan's economy depends on agriculture, and agriculture is the main dominant sector of the country, but due to repaid growth of industrial sector in Pakistan, the agriculture land is cutting. Besides this, rapid increase in population causes deforestation; Pakistan is top ranked country in Asian countries that faces the problem of deforestation. Increase in economic growth and industrial sectors use energy for growth that causes environmental degradation. Pakistan is facing high demand of energy for which traditional energy sources are used to meet its fast increasing demand for energy. Wolde-Rufael and Menyah (2010) stated that use of traditional energy resources causes to discharges carbon dioxide that helps to deteriorate environmental quality. Ahmed et al. (2015) stated that environmental degradation affect the environment and health of the human being in Pakistan. Yang and Li (2017) stated that environmental degradation is caused by vast amount of greenhouse gas emissions, including carbon dioxides, nitrous oxide, and methane. Shahbaz et al. (2013) stated that use of fossil fuels for daily life, massive smoke expulsion from the factories and consumption of wood as an energy

(c) The Author(s). 2020 Open Access This article is distributed under the terms of the Creative Commons Attribution 4.0 International License (http://creativecommons.org/licenses/by/4.0/), which permits unrestricted use, distribution, and reproduction in any medium, provided you give appropriate credit to the original author(s) and the source, provide a link to the Creative Commons license, and indicate if changes were made. 
source boost the $\mathrm{CO} 2$ emissions. Carbon dioxide emissions have a destructive impact on the economy and other sectors such as agriculture and forestry.

Chaudhry (2010); Pao and Tsai (2010); Siddiqui (2004) investigated the association between energy consumption, economic growth, and sustainable environment. Most researches have been done for developed countries such as European countries and American countries (Kasman and Selman 2015). Early researches on the same subject have generally concluded that the development of economy and energy consumption causes the $\mathrm{CO}_{2}$ emissions.

Several research studies have pointed out the relationship between the development of the economy, non-renewable energy and $\mathrm{CO} 2$ emissions, that is essential for understanding and refining the development pattern of developing countries like Pakistan. The societies which have gifted with plentiful natural resources can efficiently mitigate import of fossil sources and emissions of carbon dioxide. Balsalobre et al. (2018) stated that energy strategy implementation is validated to decrease dependence on the use of non-renewable energy sources. Non-renewable energy sources still profoundly influence the energy mix. This explicates the sustainability of both energy sources, i.e., renewable and non-renewable that may occur in the long-run.

The main objective of this research study is to investigate the association between energy consumption, economic growth, and carbon dioxide emission in Pakistan. Different researchers identified that environmental degradation is caused by using non-renewable energy consumption and economic growth in developed countries. This research study will help to clear the gap between early researches by controlling the model for energy consumption, economic growth, and CO2 emissions. This research study used newly developed econometric techniques the Auto-Regressive Distributive Lag (ARDL) bound testing for cointegration. ARDL model have different advantages as compared to other cointegration method. ARDL model can be applied if the variables are stationary at level or first difference of both of them while other cointegration methods need same order of integration. Different lag can be used for dependent and independent variables (Pesaran et al. (2001). This study will provide a new vision for policymakers to design key policy instruments on balancing economic growth and environmental quality.

\section{Literature review}

Acar and Lindmark (2017) investigated the convergence of CO2 emissions in OECD countries by using (oil vs. coal) as energy source. The authors divided the study period into two sub-periods. The first period covers the oil price shocks of OPEC, where the OECD oil policy was to a great extent governed by energy security concerns and Cold War strategic considerations. The second period correspond rise climate policy in several OECD countries. Due to such contextual differences, oil and coal behave differently in the two sub-periods on economic growth.

Asumadu-Sarkodie and Owusu (2017a, 2017b) stated that long-run equilibrium associations exist between environmental degradation, electricity use, economic growth and industrialization. The examined results of variance decomposition indicated that use of electricity and economic growth increase the environmental degradation by $7 \% 20 \%$ respectively. They recommended that in future using clean energy can decrease environmental degradation in Sierra Leone. 
Destek (2017) indicated that economic development is positively affected by nonrenewable biomass energy consumption countries. Fan and Lei (2017) examined the associations between environmental degradation transportation and economic development in Beijing by using time series data for econometric analysis from 1995 to 2014 . The estimated results pointed out that transportation and $\mathrm{CO} 2$ emissions have a positive influence on economic growth.

Işik et al. (2017) applied Autoregressive distributed lag (ARDL) model to check the association between the study variables. The estimated results revealed that economic growth, the growth of financial system, international trade and tourism expenditures positively impact the Greece's $\mathrm{CO} 2$ emissions. They stated that tourism, as a leading sector in the Greek economy, has severe negative environmental impacts for Greece in the long run. Therefore, they suggested that Greece should actively take into consideration this threat from the tourism sector as this one sector dominates the whole Greek economy.

Isik et al. (2019) investigated the impact of real GDP, population, and renewable energy and fossil energy consumptions on CO2 emissions in ten US states from 1980 to 2015. The examined results indicated that the EKC hypothesis is valid for the following states Florida, Illinois, Michigan, New York, and Ohio. The results indicated that fossil energy consumption have negative impacts on $\mathrm{CO} 2$ emission levels in Texas while energy consumption having positively influence on $\mathrm{CO} 2$ emissions in Florida but this impact is lower as compared to other states of US.

Azam et al. (2016) inspected the influences of CO2 emissions, energy use, trade, and human capital on economy growth from 1971 and 2013 for China, the USA, India, and Japan by utilizing panel fully modified ordinary least squares (FMOLS) for checking the association among the study variables. The examined results pointed out that $\mathrm{CO} 2$ emissions and energy consumption negatively and significantly influences the economic growth while trade and human capital positively and significantly influences the economic growth.

Hanif (2018) studied the influences of economic growth; urban expansion; and consumption of fossil fuels, solid fuels, and renewable energy on CO2 emission in SubSaharan Africa economies from 1995 to 2015 by utilizing the GMM model for examination of the association among the study variables. The examined results indicated that consumption of fossil and solid fuels positively impact the $\mathrm{CO} 2$ emissions while renewable energy helps to decrease the $\mathrm{CO} 2$ emissions.

Saboori et al. (2017) examined the association of oil consumption, economic growth and with environmental degradations in three Asian countries from 1980 to 2013 by applying Johansen cointegration test for checking the relationship among the study variables. The examined results indicated that uni-directional causality running from oil consumption to economic growth in China and Japan, while oil consumption to CO2 emissions in South Korea.

Bhat (2018) studied the impact of energy consumption, economic growth on carbon dioxide from 1992 to 2016 by utilizing Panel ARDL model for checking the association among the study variables. The examined results indicated that capital, labor, population, per-capita income, and non-renewable energy consumption positively impact the $\mathrm{CO} 2$ emissions.

Sulaiman and Abdul-Rahim (2017) investigated the association of CO2 emission, energy consumption and economic in Malaysia from 1975 to 2015 by utilizing ARDL 
model. The examined results indicated that economic growth is not impacted by by energy consumption and $\mathrm{CO} 2$ emission while energy consumption and economic growth positively influence the $\mathrm{CO} 2$ emission.

Tamba et al. (2017) inspected the impact of gasoline energy consumption on economic growth in Cameroon by utilizing autoregressive vector (VAR) model and Wald test for testing causality. The estimated results showed that no long-term relationship exists among the study variables. Bidirectional causality relationship between gasoline consumption and economic growth exists in Cameroon. The estimated results showed that reducing gasoline consumption without appropriate and established energy policies are not a possible solution to maintain Cameroon's economic growth.

Apergis et al. (2010) and Zoundi (2017) stated that renewable energy exploitation was restricted by different conditions and the level of economic growth in the low-income countries. Sinha and Shahbaz (2018) stated that the high cost of initial stage of renewable energy development results demotivate in developing countries to invest in renewable energy sources. It appears that promoting renewable energy in some low-income countries may lead to restrain their economic progress in the short run. Inglesi-Lotz and Dogan (2018) suggested that shifting energy consumption away from fossil fuels to renewable energy sources is a challenge for developing countries. Different energy structures between the developing and developed countries are different because of technological and economic conditions.

\section{Methodology}

\section{Unit root test}

Stationarity in time series data is a common problem. It is necessary to check the stationarity of the variables before using ARDL model. Traditional methods for assessment in applied econometrics are based on the supposition of normality saying mean, and variance does not change over time. However, the mean and variance of many economic elements do not remain constant and such type of variables is known as unit root variables. Traditional approach (i.e., ordinary least square, OLS) produces biased and unreliable estimates in the presence of stationary data. In this research, we used a great unit root test, such as PP (Phillips and Perron 1988), ADF (Dickey et al. 1979). Our empirical analysis checks stationarity of each variable by applying PP and ADF unit root test.

\section{Autoregressive distributive lag}

Time series data for this study was collected from world development indicator World Bank, from 1965 to 2015. The selection choice of the period was based on the data availability. Carbon dioxide emissions is used as a measure for environmental degradation, and it is measured as $\mathrm{CO}_{2}$ emission per capita, PCI is used as proxy for economic growth, measured as percentage of gross domestic product (constant 2010 USD), CLCNM is coal consumption, OLCNM is oil consumption, NTGCNM is the natural gas consumption are explanatory variables. Following is the main regression equation for our variables.

$$
\mathrm{CO} 2 \mathrm{em}_{t}=\beta_{0}+\beta_{1} \mathrm{PCI}_{t}+\beta_{2} \mathrm{CLCNM}_{t}+\beta_{3} \mathrm{OLCNM}_{t}+\beta_{4} \mathrm{NTGCNM}_{t}+\varepsilon_{t}
$$

Following previous researchers Jebli and Youssef (2015a, 2015b), Jebli and Youssef (2015a, 2015b) and Alshehry and Belloumi (2015) and Khan et al. (2017, 2019a, b) in this study we use the bound testing approach proposed by Pesaran et al. (2001) to 
estimate the long run estimates between $\mathrm{CO}_{2}$ emission, economic growth, energy consumption. Prior studies in energy economics suggest several econometric approaches to check the existence of the cointegration. However, the bound testing approach was preferred due to several reasons. The ARDL bound testing method is most suitable when the variables are integrated at the order of $1(0)$ or 1(1). Besides, it is useful when data size is small. The lag modification in the ARDL model gives fair estimations of the long run and effective $t$-statistic value even in the presence of endogeneity (Pesaran et al. 2001). Therefore, this study applied the ARDL method to investigate cointegration among energy consumption, economic growth, and $\mathrm{CO}_{2}$ emission.

The ARDL Bound testing approach is given by the following equations:

$$
\begin{aligned}
& \Delta C O 2 e m_{t}=\beta_{0}+\sum_{i=1}^{q 1} \beta_{1 i} \Delta C O 2 e m_{t-i}+\sum_{i=1}^{q 2} \beta_{2 i} \Delta P C I_{t-i}+\sum_{i=1}^{q 3} \beta_{3 i} \Delta C L C N M_{t-i} \\
& +\sum_{i=1}^{q 4} \beta_{4 i} \Delta O L C N M_{t-i}+\sum_{i=1}^{q 5} \beta_{5 i} \Delta N T G C N M_{t-i}+\delta_{0} C O 2 e m_{t-i}+\delta_{1} P_{C I} I_{t-i} \\
& +\delta_{2} \operatorname{CLCNM}_{t-i}+\delta_{3} \mathrm{OLCNM}_{t-i}+\delta_{4} \mathrm{NTGCNM}_{t-i}+\mu_{t} \\
& \Delta P C I_{t}=\beta_{0}+\sum_{i=1}^{q 1} \beta_{1 i} \Delta P C I_{t-i}+\sum_{i=1}^{q 2} \beta_{2 i} \Delta C O 2 e m_{t-i}+\sum_{i=1}^{q 3} \beta_{3 i} \Delta C L C N M_{t-i} \\
& +\sum_{i=1}^{q 4} \beta_{4 i} \Delta O L C N M_{t-i}+\sum_{i=1}^{q 5} \beta_{5 i} \Delta N T G C N M_{t-i}+\delta_{0} P C I_{t-i}+\delta_{1} \text { CO2em }_{t-i} \\
& +\delta_{2} \text { CLCNM }_{t-i}+\delta_{3} \text { OLCNM }_{t-i}+\delta_{4} N T G C N M_{t-i}+\mu_{t} \\
& \Delta C L C N M_{t}=\beta_{0}+\sum_{i=1}^{q 1} \beta_{1 i} \Delta C L C N M_{t-i}+\sum_{i=1}^{q 2} \beta_{2 i} \Delta C O 2 e m_{t-i}+\sum_{i=1}^{q 3} \beta_{3 i} \Delta P C I_{t-i} \\
& +\sum_{i=1}^{q 4} \beta_{4 i} \Delta O L C N M_{t-i}+\sum_{i=1}^{q 5} \beta_{5 i} \Delta N T G C N M_{t-i}+\delta_{0} \operatorname{CLCNM}_{t-i} \\
& +\delta_{1} \mathrm{CO}_{2 e m_{t-i}}+\delta_{2} \mathrm{PCI}_{t-i}+\delta_{3} \mathrm{OLCNM}_{t-i}+\delta_{4} \mathrm{NTGCNM}_{t-i}+\mu_{t} \\
& \Delta O L C N M_{t}=\beta_{0}+\sum_{i=1}^{q 1} \beta_{1 i} \Delta O L C N M_{t-i}+\sum_{i=1}^{q 2} \beta_{2 i} \Delta C O 2 e m_{t-i}+\sum_{i=1}^{q 3} \beta_{3 i} \Delta P C I_{t-i} \\
& +\sum_{i=1}^{q 4} \beta_{4 i} \Delta C L C N M_{t-i}+\sum_{i=1}^{q 5} \beta_{5 i} \Delta N T G C N M_{t-i}+\delta_{0}{ }^{2} L C N M_{t-i} \\
& +\delta_{1} \text { CO2em }_{t-i}+\delta_{2} P_{C I-i}+\delta_{3} \operatorname{CLCNM}_{t-i}+\delta_{4} N T G C N M_{t-i}+\mu_{t} \\
& \Delta N T G C N M_{t}=\beta_{0}+\sum_{i=1}^{q 1} \beta_{1 i} \Delta N T G C N M_{t-i}+\sum_{i=1}^{q 2} \beta_{2 i} \Delta C O 2 e m_{t-i}+\sum_{i=1}^{q 3} \beta_{3 i} \Delta P C I_{t-i} \\
& +\sum_{i=1}^{q 4} \beta_{4 i} \Delta C L C N M_{t-i}+\sum_{i=1}^{q 5} \beta_{5 i} \Delta O L C N M_{t-i}+\delta_{0} N Y G C N M_{t-i} \\
& +\delta_{1} \mathrm{CO}_{2 e m_{t-i}}+\delta_{2} \mathrm{PCI}_{t-i}+\delta_{3} \mathrm{CLCNM}_{t-i}+\delta_{4} \mathrm{OLCNM}_{t-i}+\mu_{t}
\end{aligned}
$$

In the above equations of the bound testing approach, first difference operation is indicated by $\Delta$, and $\mu_{t}$ is the residual term. The null hypothesis to be tested is $H_{o}: \delta_{0}=$ 
$\delta_{1}=\delta_{2}=\delta_{3}=\delta_{4}=0$ and alternative hypothesis $H_{0}: \delta_{0} \neq \delta_{1} \neq \delta_{2} \neq \delta_{3} \neq \delta_{4} \neq 0$ indicating the long run association between the study variables. Cointegration is based on the results of the F value in the bound testing approach. If the calculated F-value exceeds the upper bound, the null hypothesis of no cointegration is rejected, but the result is considered un-decidable when the F-value lies between upper and lower bound values. The error correction model for the estimation of the short-run relationships is specified as:

$$
\begin{aligned}
& \Delta C O 2 \mathrm{em}_{t}=\beta_{0}+\sum_{i=1}^{q 1} \beta_{1 i} \Delta C O 2 e m_{t-i}+\sum_{i=0}^{q 2} \beta_{2 i} \Delta P C I_{t-i}+\sum_{i=0}^{q 3} \beta_{3 i} \Delta C L C N M_{t-i} \\
& +\sum_{i=0}^{q 4} \beta_{4 i} \Delta O L C N M_{t-i}+\sum_{i=0}^{q 5} \beta_{5 i} \Delta N T G C N M_{t-i}+\eta_{1} E C T_{t-i}+\mu_{t} \\
& \Delta P C I_{t}=\beta_{0}+\sum_{i=1}^{q 1} \beta_{1 i} \Delta P C I_{t-i}+\sum_{i=0}^{q 2} \beta_{2 i} \Delta C O 2 e m_{t-i}+\sum_{i=0}^{q 3} \beta_{3 i} \Delta C L C N M_{t-i} \\
& +\sum_{i=0}^{q 4} \beta_{4 i} \Delta O L C N M_{t-1}+\sum_{i=0}^{q 5} \beta_{5 i} \Delta N T G C N M_{t-i}+\eta_{2} E C T_{t-i}+\mu_{t} \\
& \Delta C L C N M_{t}=\beta_{0}+\sum_{i=1}^{q 1} \beta_{1 i} \Delta C L C N M_{t-i}+\sum_{i=0}^{q 2} \beta_{2 i} \Delta C O 2 e m_{t-i}+\sum_{i=0}^{q 3} \beta_{3 i} \Delta P C I_{t-i} \\
& +\sum_{i=0}^{q 4} \beta_{4 i} \Delta O L C N M_{t-i}+\sum_{i=0}^{q 5} \beta_{5 i} \Delta N T G C N M_{t-i}+\eta_{3} E C T_{t-i}+\mu_{t} \\
& \Delta O L C N M_{t}=\beta_{0}+\sum_{i=1}^{q 1} \beta_{1 i} \Delta O L C N M_{t-i}+\sum_{i=0}^{q 2} \beta_{2 i} \Delta C O 2 e m_{t-i}+\sum_{i=0}^{q 3} \beta_{3 i} \Delta P C I_{t-i} \\
& +\sum_{i=0}^{q 4} \beta_{4 i} \Delta C L C N M_{t-i}+\sum_{i=0}^{q 5} \beta_{5 i} \Delta N T G C N M_{t-i}+\eta_{4} E C T_{t-i}+\mu_{t} \\
& \Delta N T G C N M_{t}=\beta_{0}+\sum_{i=1}^{q 1} \beta_{1 i} \Delta N T G C N M_{t-i}+\sum_{i=0}^{q 2} \beta_{2 i} \Delta C O 2 e m_{t-i}+\sum_{i=0}^{q 3} \beta_{3 i} \Delta P C I_{t-i} \\
& +\sum_{i=0}^{q 4} \beta_{4 i} \Delta C L C N M_{t-i}+\sum_{i=0}^{q 5} \beta_{5 i} \Delta O L C N M_{t-i}+\eta_{5} E C T_{t-i}+\mu_{t}
\end{aligned}
$$

In the above equations $\eta_{1}$ to $\eta_{5}$ indicating the speed of adjustment, $E C T_{t-i}$ is the lagged error correction term. $E C T_{t-i}$ is expected to be negative and significant. The CUSUM and CUSMSQ are also used for model stability check (Brown et al. 1975). Breusch-Godfrey is used for checking the serial correlation, and Breusch-PaganGodfrey was used for checking Heteroskedasticity.

\section{Results and discussions (Table 1)}

Before considering the long run ARDL model, we checked the stationary level of each variable. The reported results claim to reject the null hypothesis of the unit root; results indicate that $\mathrm{CO} 2$ emissions, Per capita income, natural gas and oil consumption are stationary at level and at first difference. The estimated results indicate that ARDL 
Table 1 Unit Root Test

\begin{tabular}{lllll}
\hline & ADF & & Phillips-Perron \\
Level & & & \\
Variables & Intercept & Trend \& Intercept & Intercept & Trend \& Intercept \\
Co2 Per Capita & -0.0105 & $-3.9313^{* *}$ & -0.1172 & -2.3169 \\
Per Capita \% Of GDP & $-6.6133^{*}$ & $-6.6682^{*}$ & $-6.6134^{*}$ & $-6.6690^{*}$ \\
Coal Consumption & -0.4811 & -1.8007 & -0.2819 & -2.5639 \\
Natural Gas Consumption & 0.2805 & -1.9188 & 0.7109 & -1.6321 \\
Oil Consumption & 1.0150 & -2.0356 & 1.2493 & -1.6065 \\
First Difference & & & & \\
Co2 Per Capita & $-6.6240^{*}$ & $-6.5945^{*}$ & $-6.6824^{*}$ & $-6.6536^{*}$ \\
Per Capita \% Of GDP & $-6.6240^{*}$ & $-11.3836^{*}$ & $-6.6824^{*}$ & $-26.4811^{*}$ \\
Coal Consumption & $-3.9032^{* *}$ & $-4.4879^{* *}$ & $-7.0700^{*}$ & $-7.1254^{*}$ \\
Natural Gas Consumption & $-3.5880^{* *}$ & $-3.7317^{* *}$ & $-3.5408^{*}$ & $-3.6997^{* *}$ \\
Oil Consumption & $-3.5999^{* *}$ & $-4.0415^{* *}$ & $-4.0651^{* *}$ & $-4.7010^{* *}$ \\
\hline
\end{tabular}

1,5 and $10 \%$ levels is indicated respectively by ${ }^{*}, *$ and ${ }^{* * *}$

model can be applied for checking the short and long run association among the study variables.

Table 2 shows the results of Lag length selection criteria for Co-integration. Usually, the researcher uses AIC and SC criteria for lag length selection because these two are superior for the small sample. We have selected AIC lag length from the above table. According to AIC lag length selection criteria lag 2 is the best option for lag length and is appropriate for ARDL approach.

Table 3 shows the results of Heteroskedasticity and serial correlation LM test. The result of Breusch Pagan Godfrey chi-square value is 0.7259 which higher than 5\%, which indicates that there is no Heteroskedasticity problem in our data. The result of the LM test shows that probability chi-square is more significant than $5 \%$ that indicates that our data is free of the problem of serial correlation.

Table 4 indicates the results of Bound test; F statistic applied for investigation of cointegration relationship. The above-estimated results are according to Narayan (2005). The empirical results show that the estimated F-statistics for $\mathrm{FCO}_{2}(\mathrm{CO} 2 \mid \mathrm{PCI}$, COLCNM, NTGCNM, OLCNM) value is 5.2017 that is higher than the upper bound value at $5 \%$, based on the estimated result of first equation co-integration exists among the variables. In the second equation, we changed the dependent variable from $\mathrm{CO} 2$ emission to per capita income $\mathrm{F}_{\mathrm{PCI}}$ (PCI|CO2, COLCNM, NTGCNM, OLCNM). Fstatistics value of the second equation indicates that cointegration exists at $5 \%$ because

Table 2 Lag length criteria for Co-integration

\begin{tabular}{lllllll}
\hline Lag & LogL & LR & FPE & AIC & SC & HQ \\
\hline 0 & -381.6793 & NA & 9.6319 & 16.4544 & 16.6513 & 16.5285 \\
1 & -140.3190 & 421.0967 & 0.0009 & 7.2476 & 8.4286 & 7.6920 \\
2 & -76.9002 & $97.1521^{*}$ & $0.0002^{*}$ & $5.6128^{*}$ & $7.7778^{*}$ & $6.4275^{*}$ \\
3 & -59.8911 & 22.4376 & 0.0003 & 5.9528 & 9.1019 & 7.1379 \\
4 & -30.7264 & 32.2673 & 0.0003 & 5.7756 & 9.9089 & 7.3309 \\
\hline 1,5 and 10\% levels is indicated respectively by *** and *** & & &
\end{tabular}


Table 3 Serial Correlation and Heteroskedasticity Test

\begin{tabular}{lcll}
\hline Breusch-Godfrey Serial Correlation LM Test & & \\
F-statistic & 1.8491 & Prob. F(2,23) & 0.1724 \\
Obs ${ }^{*}$ R-squared & 4.6827 & Prob. Chi-Square(2) & 0.0962 \\
Heteroskedasticity Test: Breusch-Pagan-Godfrey & & \\
F-statistic & 0.6425 & Prob. F(25,6) & 0.7808 \\
Obs ${ }^{*}$ R-squared & 7.8589 & Prob. Chi Square(12) & 0.7259 \\
\hline
\end{tabular}

1,5 and $10 \%$ levels is indicated respectively by *, **and ***

the F-statistics value is 11.2702 that is higher than the upper bound. In third equation $\mathrm{F}_{\mathrm{COLCNM}}$ (COLCNM|CO2, PCI, NTGCNM, OLCNM) we used coal consumption as the dependent variable, results show that F-statistics value is 14.0254 that is higher than upper bound, results of F-statistics indicates the long run relationship of the third equation. In the fourth equation of bound test, we used $\mathrm{F}_{\mathrm{NTGCNM}}$ (NTGCNM|CO2, PCI, COLCNM, OLCNM) natural gas consumption as the dependent variable. Fstatistics result indicates a long-run relationship between the variables at $5 \%$. In the last equation we used oil consumption as dependent variable $\mathrm{F}_{\mathrm{OLCNM}}$ (OLCNM|CO2, PCI, COLCNM, NTGCNM), F-statistics indicate no-long run association among variables because the F-statistics value is between the lower and upper bound at $5 \%$.

Table 5 shows the results of long-run coefficients of ARDL model; $\mathrm{CO}_{2}$ emission per capita is the dependent variable. Three proxies were used for measuring energy consumption, i.e., coal consumption, natural gas consumption, and oil consumption and per capita income is used to measure the economic growth in Pakistan.

Non-renewable energy resources have a positive and significant effect on environmental degradation. Coal consumption indicates positively effect on $\mathrm{CO} 2$ emissions in Pakistan. $1 \%$ increase in consumption of coal for energy use increase $\mathrm{CO}_{2}$ emissions up to $6.70 \%$ in Pakistan. Another source of non-renewable energy is natural gas that is mostly used for energy consumption in Pakistan; the coefficient of natural gas indicates the positive and statistically non-significant effect on $\mathrm{CO} 2$ emissions in Pakistan. The coefficient of natural gas indicates that $1 \%$ increase in the use of natural gas for energy consumption boosts environmental degradation 3.05\% in Pakistan. Oil consumption is the primary source of energy consumption in Pakistan, and the coefficient indicates a

Table 4 Bounds test for the existence of Co-Integration

\begin{tabular}{|c|c|c|}
\hline Dependent variables & F-Statistics & Outcomes \\
\hline $\mathrm{F}_{\mathrm{CO} 2}(\mathrm{CO} 2 \mid \mathrm{PCl}, \mathrm{COLCNM}, \mathrm{NTGCNM}, \mathrm{OLCNM})$ & 5.2017 & Co-integration \\
\hline $\mathrm{F}_{\mathrm{PCl}}(\mathrm{PC} \mid \mathrm{CO} 2, \mathrm{COLCNM}, \mathrm{NTGCNM}, \mathrm{OLCNM})$ & 11.2702 & Co-integration \\
\hline FCOLCNM (COLCNMICO2, PCI, NTGCNM, OLCNM) & 14.0254 & Co-integration \\
\hline $\mathrm{F}_{\text {NTGCNM }}(\mathrm{NTGCNM} \mid \mathrm{CO} 2, \mathrm{PCl}, \mathrm{COLCNM}, \mathrm{OLCNM})$ & 6.6677 & Co-integration \\
\hline FolCNM (OLCNM|CO2, PCI, COLCNM, NTGCNM) & 3.6615 & Inconclusive \\
\hline \multicolumn{3}{|l|}{ Critical Bounds Values } \\
\hline Significance & I(0) Bound & I(1) Bound \\
\hline $10 \%$ & 2.45 & 3.52 \\
\hline $5 \%$ & 2.86 & 4.01 \\
\hline $2.5 \%$ & 3.25 & 4.49 \\
\hline $1 \%$ & 3.74 & 5.06 \\
\hline
\end{tabular}


Table 5 Long Run ARDL Results

\begin{tabular}{lllll}
\hline Variable & Coefficient & Std. Error & t-Statistic & Prob. \\
\hline Coal consumption & 0.0670 & 0.0316 & 2.1202 & 0.0408 \\
Natural gas consumption & 0.0305 & 0.0374 & 0.8156 & 0.4200 \\
Oil consumption & 0.0009 & 0.0002 & 4.2382 & 0.0001 \\
Per capita income & 0.0103 & 0.0071 & 1.4388 & 0.1586 \\
C & 0.2012 & 0.0339 & 5.9396 & 0.0000 \\
\hline
\end{tabular}

positive and statistically significant effect on environmental degradation in Pakistan. 1\% increase in Oil consumption for energy production or industrial production in the economy enforce to increase environmental degradation by $0.09 \%$ in Pakistan. The findings are supported by Dogan and Seker (2016), Jebli et al. (2016), Ali et al. (2015), and Shahbaz et al. (2014). It is observed from the previous studies that the use of nonrenewable energy natural resource increases pollution and degrades environmental quality by contributing to $\mathrm{CO} 2$ emission. Mostly these resources of non-renewable energy are used for economic activities in developing countries that cause the degradation of the environment in of $\mathrm{CO} 2$ emissions. In practice, this requires the governments to take wide-ranging initiatives to diversify its energy supply, in the long run, to meet increasing demand and also attract foreign investors who provide green production technologies and capital.

Economic activities in developing countries also cause environmental degradation because these countries are using non-renewable energy resources for industrial and other economic activities that boost $\mathrm{CO} 2$ emissions in society. Concerning the environmental impact of economic growth, economic growth has a positive and statistically non-significant effect on environmental degradation. Estimated results show that when economic growth in Pakistan increases in shape of industrial development or any other economic activity the $\mathrm{CO}_{2}$ emissions also increases. The coefficient of per capita shows that $1 \%$ elevation in economic growth increases environmental degradation in the economy of Pakistan about 1.03\%. Ang (2007) stated that economic growth has a positive effect on $\mathrm{CO} 2$ emission, degradation of the environment is caused by economic growth and industrial development. Arouri et al. (2012) also stated that GDP growth is the primary cause of environmental degradation in MENA countries (Table 6).

Results of short-run ARDL are same as long-run ARDL model. Coal consumption, oil consumption, and natural gas consumption are the primary source of nonrenewable energy consumption in Pakistan. Results of non-renewable energy consumption indicate a positive impact on environmental degradation in Pakistan. Economic growth also causes environmental degradation due to repaid growth of industries and

Table 6 Short Run ARDL Results

\begin{tabular}{lllll}
\hline Variable & Coefficient & Std. Error & t-Statistic & Prob. \\
\hline D (Coal consumption) & 0.0374 & 0.0118 & 3.1812 & 0.0030 \\
D (Natural gas consumption) & 0.1119 & 0.0388 & 2.8809 & 0.0066 \\
D (Natural gas consumption(- 1)) & 0.0969 & 0.0373 & 2.6008 & 0.0133 \\
D (Oil consumption) & 0.0012 & 0.0002 & 4.7727 & 0.0000 \\
D (Per capita income) & 0.0027 & 0.0015 & 1.8763 & 0.0685 \\
ECT(-1) & -0.2682 & 0.1034 & -2.5935 & 0.0135 \\
\hline
\end{tabular}


Table 7 Diagnostics Test

\begin{tabular}{llll}
\hline R-squared & 0.9950 & Akaike info criterion & -5.0097 \\
Adjusted R-squared & 0.9935 & Schwarz criterion & -4.5464 \\
F-statistic & 669.4427 & Durbin-Watson stat & 2.4669 \\
Prob(F-statistic) & & 0.0000 & \\
\hline
\end{tabular}

other sectors in the economy. Economic growth indicates a positive effect on the degradation of the environment in Pakistan. It is average in developing countries economy when the economic growth increases, so it causes to raise the $\mathrm{CO} 2$ emissions in the economy because of the economic activities in shape of a considerable number of factories which cause $\mathrm{CO} 2$ emissions. The coefficient of ECT is negative and statistically significant that suggests that any change in $\mathrm{CO} 2$ emissions from short-run towards long period is accurate by $26.81 \%$ every year (Table 7 ).

The above shows the diagnostics test. The r-squared value indicates that $99 \%$ variation independent variable is explained by coal consumption, oil consumption, natural gas consumption these three are used for measuring energy consumption and per capita income which is used to measure economic growth. AIC and SIC showed that the model is fit; Durbin Watson indicates that there is no problem of autocorrelation in our data (Figs. 1 and 2).

CUSUM and CUSUM of squares indicate that the model is stable because the blue line among the two red lines which shows the stability of coefficients.

\section{Conclusions and recommendations}

This primary objective of this paper is to examine the nexus between energy consumption, economic growth and $\mathrm{CO}_{2}$ emission in Pakistan from 1965 to 2015. Stationarity of each time series was checked through Augmented Dickey-Fuller (ADF) and PhillipsPerron (PP) Unit Root Tests. The results of the Augmented Dickey-Fuller (ADF) and Phillips-Perron (PP) Unit Root Tests indicated that all the time series are stationary at

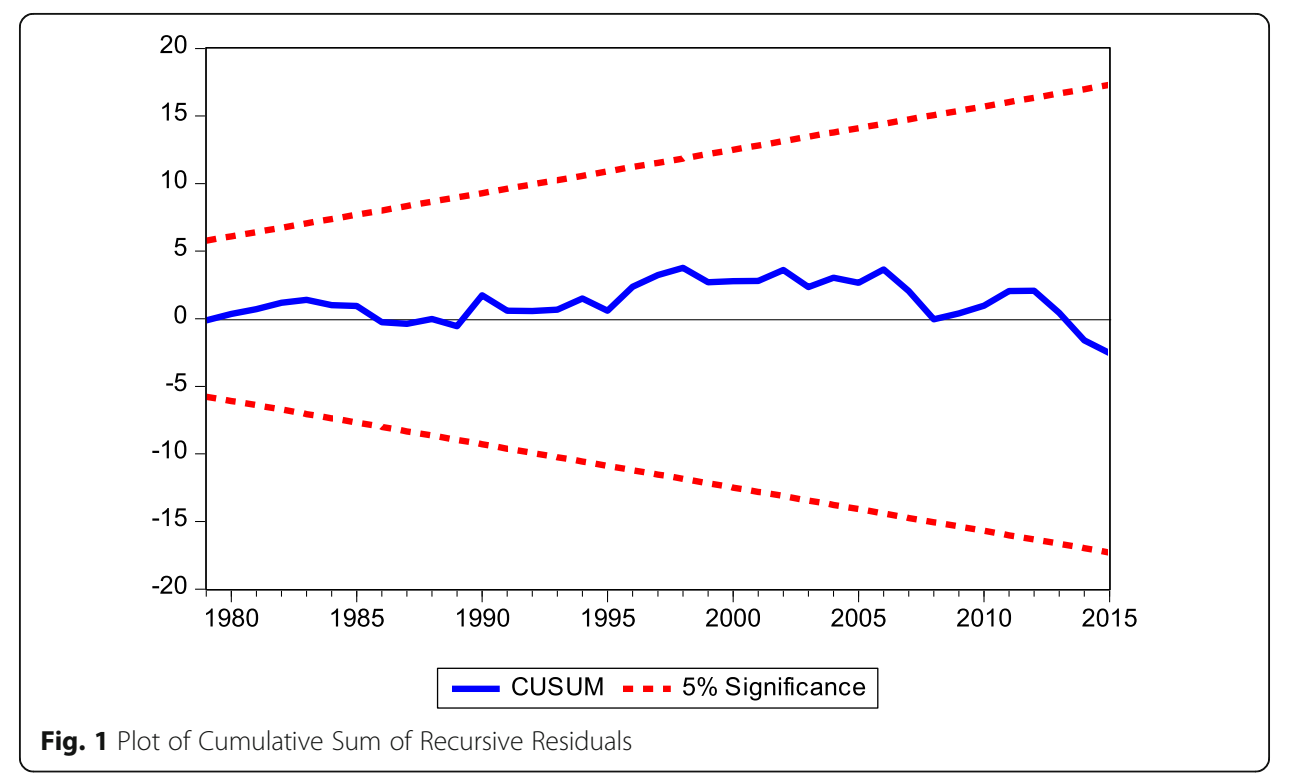




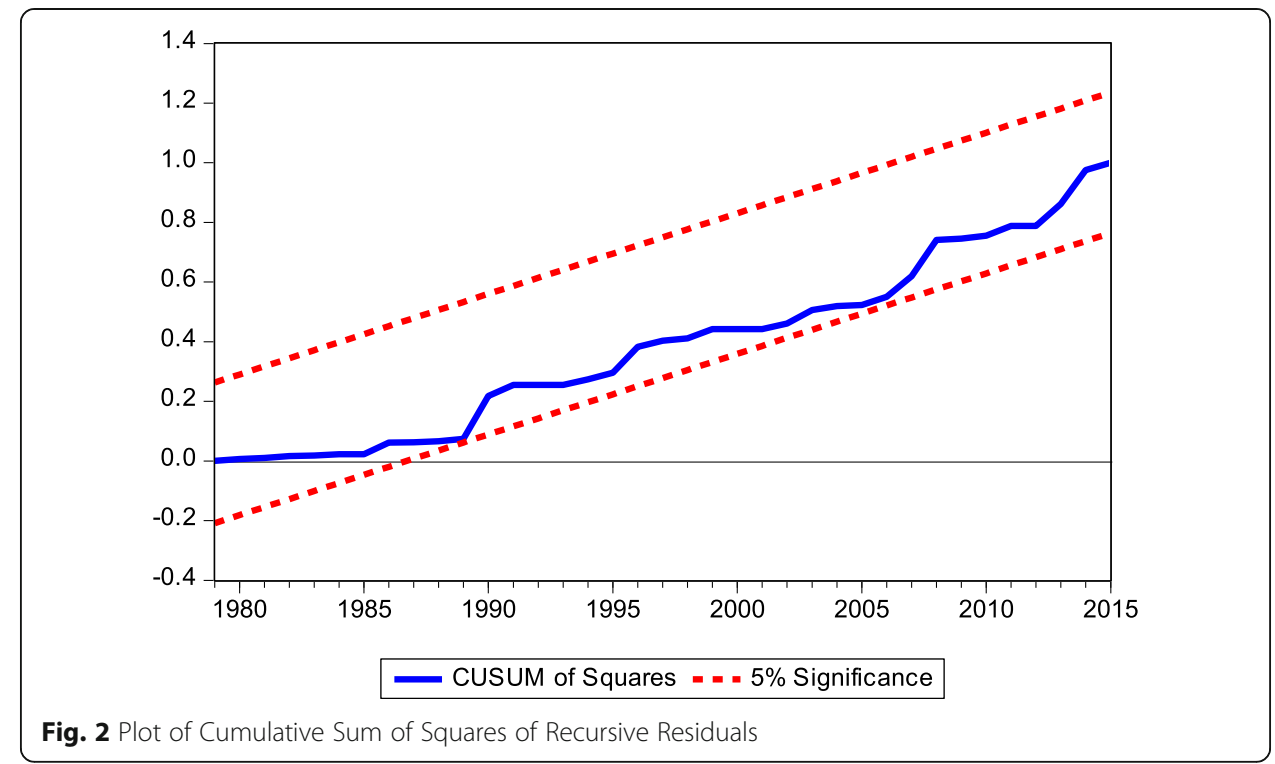

level and first difference and none of the series are at second difference. Autoregressive distributed lag (ARDL) is applied for checking cointegration among the series. Long run ARDL results pointed out that energy consumption have a positive effect on $\mathrm{CO} 2$ emissions in Pakistan. Coefficient of economic growth indicates a positive effect on the $\mathrm{CO} 2$ emissions in Pakistan both short and long run.

Based on the results of this study, it is recommended that government of Pakistan should educate the local people to motive them toward plantation with forest department to increase the share of the forest to control environmental degradation in Pakistan. Estimated results indicated that environmental degradation is the main cause of economic growth so it is recommended to revise policy related to economic growth in Pakistan for controlling the environmental degradations. Non-renewable sources of energy are used as a fuel and for industrial production and household energy consumption in Pakistan so it is recommended to adopt such energy sources that cause minimum environmental degradation. To control the environmental degradations in the long run, the policy makers are recommended to adopt such policies that encourage using environment-friendly equipment, machinery, vehicles, and utilities to minimize the environmental degradations.

\section{Abbreviations}

ADF: Augmented Dickey-Fuller; ARDL: Autoregressive distributed lag; CO2: Carbon Dioxide emissions; COLCNM: Coal Consumption; ECM: Error correction model; NTGCNM: Natural gas consumptions; OLCNM: Oil consumptions; PCl: Per capita income is used for Economic growth; PP: Phillips and Perron

Authors' contributions

We are very thankful to all friends for their help and suggestion their valuable comments regarding this research paper. Currently this research paper did not receive any financial aid from any source. 
Availability of data and materials

The data used in this research paper were obtained from the World Development indicator (World Bank): https://data. worldbank.org/products/wdi

\section{Competing interests}

The authors declare that they have no competing interests.

Received: 12 November 2018 Accepted: 20 November 2019

Published online: 08 January 2020

\section{References}

Acar S, Lindmark M (2017) Convergence of CO2 emissions and economic growth in the OECD countries: did the type of fuel matter? Energy Sources Part B: Econ Planning Policy 12(7):618-627

Ahmad A, Zhao Y, Shahbaz M, Bano S, Zhang Z, Wang S, Liu Y (2015) Carbon emissions, energy consumption and economic growth: An aggregate and disaggregate analysis of the Indian economy. Energy Policy, 96, 131-143

Ali A, Khatoon S, Ather M, Akhtar N (2015) Modeling energy consumption, carbon emission and economic growth: Empirical analysis for Pakistan. International Journal of Energy Economics and Policy, 5(2), 624-630

Alshehry AS, Belloumi M (2015) Energy consumption, carbon dioxide emissions, and economic growth: the case of Saudi Arabia. Renew Sust Energ Rev 41:237-247

Ang JB (2007) CO2 emissions, energy consumption, and output in France. Energy Policy 35:4772-4778

Apergis N, Payne JE, Menyah K, Wolde-Rufael Y (2010) On the causal dynamics between emissions, nuclear energy, renewable energy, and economic growth. Ecol Econ 69(11):2255-2260

Arouri MEH, Youssef AB, M'henni H, Rault C (2012) Energy consumption, economic growth and CO 2 emissions in the Middle East and north African countries. Energy Policy 45:342-349

Asumadu-Sarkodie S, Owusu PA (2017a) A multivariate analysis of carbon dioxide emissions, electricity consumption, economic growth, financial development, industrialization, and urbanization in Senegal. Energy Sources Part B: Econ Planning Policy 12(1):77-84

Asumadu-Sarkodie S, Owusu PA (2017b) The causal effect of carbon dioxide emissions, electricity consumption, economic growth, and industrialization in Sierra Leone. Energy Sources Part B: Econ Planning Policy 12(1):32-39

Azam M, Khan AQ, Abdullah HB, Qureshi ME (2016) The impact of CO 2 emissions on economic growth: evidence from selected higher CO 2 emissions economies. Environ Sci Pollut Res 23(7):6376-6389

Balsalobre-Lorente D, Shahbaz M, Roubaud D, Farhani S (2018) How economic growth, renewable electricity and natural resources contribute to $\mathrm{CO} 2$ emissions?. Energy Policy, 113, 356-367

Bhat JA (2018) Renewable and non-renewable energy consumption-impact on economic growth and CO 2 emissions in five emerging market economies. Environ Sci Pollut Res 25(35):35515-35530

Brown RL, Durbin J, Evans JM (1975) Techniques for testing the constancy of regression relationships over time. J R Stat Soc Ser B Methodol 37(2):149-163.

Chaudhry AA (2010) A panel data analysis of electricity demand in Pakistan

Destek MA (2017) Biomass energy consumption and economic growth: evidence from top 10 biomass consumer countries. Energy Sources Part B: Econ Planning Policy:1-6

Dickey, D.A, Fuller, W.A (1979) Distribution of the estimators for autoregressive time series with a unit root. Journal of the American statistical 10.1186/s40854-019-0162-0 association, 74(366a), 427-431

Dogan E, Seker F (2016) The influence of real output, renewable and non-renewable energy, trade and financial development on carbon emissions in the top renewable energy countries. Renewable and Sustainable Energy Reviews, $60,1074-1085$

Fan F, Lei Y (2017) The responsive relationship between energy-related carbon dioxide emissions from the transportation sector and economic growth in Beijing - based on decoupling theory. Int I Sustainable Transport 11(10):764-775

Hanif I (2018) Impact of economic growth, nonrenewable and renewable energy consumption, and urbanization on carbon emissions in sub-Saharan Africa. Environ Sci Pollut Res 25(15):15057-15067

Inglesi-Lotz R, Dogan E (2018) The role of renewable versus non-renewable energy to the level of CO2 emissions a panel analysis of sub-Saharan Africa's Big 10 electricity generators. Renew Energy 123:36-43

ışik C, Kasımatı E, Ongan S (2017) Analyzing the causalities between economic growth, financial development, international trade, tourism expenditure and/on the CO2 emissions in Greece. Energy Sources Part B: Econ Planning Policy 12(7):665673

Işı C, Ongan S, Özdemir D. (2019). Testing the EKC hypothesis for ten US states: an application of heterogeneous panel estimation method. Environmental Science and Pollution Research 26(11) 10846-10853

Jebli MB, Youssef SB (2015a) Economic growth, combustible renewables, and waste consumption, and CO2 emissions in North Africa. Environ Sci Pollut Res 22(20):16022-16030

Jebli MB, Youssef SB (2015b) The environmental Kuznets curve, economic growth, renewable and non-renewable energy, and trade in Tunisia. Renew Sust Energ Rev 47:173-185

Jebli M.B, Youssef S.B, Ozturk I (2016) Testing environmental Kuznets curve hypothesis: The role of renewable and nonrenewable energy consumption and trade in OECD countries. Ecological Indicators, 60, 824-831

Kasman A, Duman Y.S (2015) CO2 emissions, economic growth, energy consumption, trade and urbanization in new EU member and candidate countries: a panel data analysis. Economic Modelling, 44, 97-103

Khan M.K, Teng J.Z, Khan M.I, Khan M.O (2019a) Impact of globalization, economic factors and energy consumption on CO2 emissions in Pakistan. Science of the total environment, 688, 424-436

Khan M.K, Teng J.Z, Khan M.I (2019b) Effect of energy consumption and economic growth on carbon dioxide emissions in Pakistan with dynamic ARDL simulations approach. Environmental Science and Pollution Research, 1-11

Khan M.K, Teng J.Z, Parvaiz J, Chaudhary S.K (2017) Nexuses between Economic Factors and Stock Returns in China International Journal of Economics and Finance, 9(9). 
Menyah K, Wolde-Rufael Y (2010) Energy consumption, pollutant emissions and economic growth in South Africa. Energy economics, 32(6), 1374-1382

Narayan P.K (2005) The saving and investment nexus for China: evidence from cointegration tests. Applied economics, 37(17), 1979-1990. Phillips, P. C., \& Perron, P. (1988). Testing for a unit root in time series regression. Biometrika, 75(2), 335-346

Pao HT, Tsai CM (2010) CO 2 emissions, energy consumption and economic growth in BRIC countries. Energy Policy 38(12): 7850-7860

Pesaran MH, Shin Y, Smith RJ (2001) Bounds testing approaches to the analysis of level relationships. J Appl Econ 16(3):289-326

Phillips P.C, Perron P (1988) Testing for a unit root in time series regression. Biometrika, 75(2), 335-346

Saboori B, Rasoulinezhad E, Sung J (2017) The nexus of oil consumption, CO 2 emissions and economic growth in China, Japan and South Korea. Environ Sci Pollut Res 24(8):7436-7455

Shahbaz M, Solarin S.A, Mahmood H, Arouri M (2013) Does financial development reduce CO2 emissions in Malaysian economy? A time series analysis. Economic Modelling, 35, 145-152

Shahbaz M, Uddin G.S, Rehman I.U, Imran K (2014) Industrialization, electricity consumption and CO2 emissions in Bangladesh. Renewable and Sustainable Energy Reviews, 31, 575-586

Siddiqui R (2004) Energy and economic growth in Pakistan. Pak Dev Rev 175-200

Sinha A, Shahbaz M (2018) Estimation of environmental Kuznets curve for CO2 emission: role of renewable energy generation in India. Renew Energy 119:703-711

Sulaiman C, Abdul-Rahim AS (2017) The relationship between CO 2 emission, energy consumption and economic growth in Malaysia: a three-way linkage approach. Environ Sci Pollut Res 24(32):25204-25220

Tamba JG, Nsouandélé JL, Lélé AF (2017) Gasoline consumption and economic growth: evidence from Cameroon. Energy Sources Part B: Econ Planning Policy 12(8):685-691

Yang L, Li Z (2017) Technology advance and the carbon dioxide emission in China-Empirical research based on the rebound effect. Energy Policy 101:150-161

Zoundi Z (2017) CO2 emissions, renewable energy and the environmental Kuznets curve, a panel cointegration approach. Renew Sust Energ Rev 72:1067-1075

\section{Publisher's Note}

Springer Nature remains neutral with regard to jurisdictional claims in published maps and institutional affiliations.

\section{Submit your manuscript to a SpringerOpen ${ }^{\circ}$ journal and benefit from:}

- Convenient online submission

- Rigorous peer review

- Open access: articles freely available online

- High visibility within the field

- Retaining the copyright to your article

Submit your next manuscript at $\boldsymbol{\nabla}$ springeropen.com 